\title{
'SÓ MACHO NA ENCOLHA': A HETERONORMATIVIDADE EM APLICATIVOS DE REDES GEOSSOCIAIS GAYS EM TERRITÓRIOS CRIATIVOS DO RIO DE JANEIRO
}

\author{
'ONLY DISCRETE MALES': HETERONORMATIVITY IN GAY GEOSOCIAL \\ NETWORKS IN CREATIVE TERRITORIES OF RIO DE JANEIRO
}

\begin{abstract}
Resumo
O objetivo é examinar a preferência pelos homens "não-afeminados" em aplicativos de redes geossociais gays em territórios criativos da cidade do Rio de Janeiro. Argumenta-se que, ainda que a cidade tenha procurado ampliar a infraestrutura bruta para o estabelecimento de indústrias criativas, o precário desenvolvimento de meios intelectuais para o estímulo efetivo ao potencial criativo e cidadão dos seus habitantes associou-se à precarização das iniciativas voltadas para o combate a LGBTfobia. Como resultado dessa dinâmica, os regimes de controle da sexualidade incorporados por meio do aprendizado social pelos membros da cultura - regimes nos quais estão inclusos usuários dos aplicativos de redes geossociais gays - continuam a naturalizar as relações heterossexuais no espaço público e fortalecer estereótipos associados à masculinidade hegemônica.
\end{abstract}

Palavras-chave: Redes geossociais. Economia criativa. Rio de Janeiro. Heteronormatividade. LGBT.

\begin{abstract}
The purpose is to examine the preference for "non-effeminate" men in gay geosocial networks in creative territories of the city of Rio de Janeiro. It is argued that, although the city sought to expand the raw infrastructure for the establishment of creative industries, the precarious development of intellectual means to effectively stimulate the creative and citizen potential of its inhabitants was associated with the precariousness of initiatives aimed at fighting LGBTphobia. Regimes of sexuality control incorporated through social learning by members of the culture - regimes that include users of gay geosocial networks - continue to naturalize heterosexual relationships in the public arena and strengthen stereotypes associated with hegemonic masculinity.
\end{abstract}

Keywords: Geosocial networks. Creative economy. Rio de Janeiro. Heteronormativity. LGBT. 
A economia criativa refere-se a um conjunto de setores que englobam bens e serviços baseados na criatividade, no talento ou na habilidade individual e as suas aplicações funcionais, que podem gerar propriedade intelectual e/ou produzir inovação que contribua para a melhoria da qualidade de vida e dos processos de gestão e produção (MIGUEZ, 2007, p.96-97). Dentre esses setores diversificados, cabe citar artesanato, artes cênicas, música, filmes e vídeo, TV e rádio, mercado editorial, publicidade, fotografia, gastronomia, turismo, desenvolvimento de softwares, engenharia de produção, arquitetura, design e moda, os quais podem viabilizar transformações sociais em face de seu potencial empregador, produtivo e inovador (FIGUEIREDO, 2015, p.34; SEN, 2000; SILVA, 2012, p.112-115).

Nesse sentido, o Rio de Janeiro foi uma das cidades ao redor do mundo que assumiram estratégias de desenvolvimento baseadas no estímulo às indústrias criativas, sendo inclusive denominada por especialistas e formuladores de decisão como uma "cidade criativa" (JESUS; KAMLOT, 2016, p.16-18). As cidades criativas, de acordo com Richard Florida (2005), devem contar com talentos que orientem seu crescimento socioeconômico, tecnologias que permitam conexões entre os profissionais criativos, os moradores e os visitantes da cidade e "tolerância à diversidade", o que contribuiria para a produção criativa e a convivência harmônica entre os cidadãos (FLORIDA, 2005). Aplicativos de redes sociais que podem ser instalados em telefones celulares e tablets ampliaram a facilidade para o estabelecimento de contatos profissionais, sentimentais, afetivos e sexuais por profissionais criativos e moradores e visitantes de cidades criativas como o Rio de Janeiro. As redes geossociais permitem aos usuários acessar outros indivíduos em estreita proximidade, trazendo perfis desses usuários e abrindo opções de bate-papo (chat), envio de fotos e exibição da distância na qual se encontram. Os aplicativos dessas redes permitem a interação entre pessoas de diferentes classes sociais, bem como de origens, faixas etárias, identidades de gênero e orientações sexuais distintas.

Um olhar mais apurado sobre os aplicativos de redes geossociais gays no Rio de Janeiro pode revelar que a aceitação plena da diferença e seu reconhecimento na dimensão de riqueza como pré-requisitos para a existência e o crescimento de uma cidade criativa não se concretizem em uma sociedade culturalmente distinta como a brasileira, mais especificamente a carioca. Inúmeros usuários de aplicativos como o Grindr e o Scruff - alguns dos mais utilizados por homens buscando relações afetivas e sexuais com outros homens no Brasil - parecem reproduzir estereótipos e valores vinculados à masculinidade hegemônica, um padrão de práticas culturalmente específicas que possibilitou a legitimação ideológica da subordinação feminina e a permanência da dominação masculina (CONNELL, 1993, p.603; CONNELL \& MESSERSCHMIDT, 2005, p.832833). Por se colocar como uma forma culturalmente idealizada, ela se diferencia interna e hierarquicamente de outras masculinidades e se sustenta socialmente pela heterossexualidade e pela homofobia (DONALDSON, 1993). Curiosamente, tanto homens heterossexuais como homossexuais parecem exaltar aspectos da masculinidade hegemônica, que os permitem diferenciar-se do modelo de homem homossexual "afeminado" ao assumirem e cultuarem o estereótipo de um homem másculo e viril (PERLONGHER, 2008, p. 79; SOUZA, 2012, p.45). A permanência da heteronormatividade - conceito que se refere às expectativas, demandas e obrigações sociais que derivam da naturalização da heterossexualidade e às prescrições que fundamentam processos sociais de regulação e controle (BUTLER, 2003; JESUS, 2014, p.44) - em cidades criativas como o Rio de Janeiro evidencia a manutenção de um regime excludente de controle da sexualidade que contraria a lógica de valorização das diferenças, necessária à expressão do potencial socioeconômico da criatividade.

O objetivo deste artigo é examinar a preferência pelos homens "não-afeminados" em aplicativos de redes geossociais gays em territórios criativos da cidade do Rio de Janeiro. Argumento que, ainda que a cidade tenha procurado ampliar a infraestrutura bruta para o estabelecimento de indústrias criativas, o precário desenvolvimento de meios intelectuais para o estímulo efetivo ao potencial criativo e cidadão dos seus habitantes - resultado da permanência de um processo educacional que prioriza o conhecimento técnico em relação à reflexão criativa e ao raciocínio crítico - associou-se à precarização das iniciativas voltadas para o combate a LGBTfobia, culminando na falta de incentivo ao respeito às diferenças 
para a produção criativa e a convivência harmônica no ambiente urbano. Como resultado dessa dinâmica, os regimes de controle da sexualidade incorporados por meio do aprendizado social pelos membros da cultura - regimes nos quais estão inclusos usuários dos aplicativos de redes geossociais gays - continuam a naturalizar as relações heterossexuais no espaço público, fortalecer estereótipos associados à masculinidade hegemônica e relegar outras masculinidades à vivência no espaço privado, como aquelas dos “afeminados". Não se geram, assim, condições de possibilidade para a aceitação plena da diferença, prérequisito para o desenvolvimento da criatividade.

$\mathrm{O}$ argumento central será desenvolvido em três partes. Primeiramente, no âmbito da discussão teóricoconceitual, analisarei os conceitos de "território criativo", "cidade criativa" e "classe criativa", desenvolvidos principalmente por autores norte-americanos e europeus, $\mathrm{e}$ a relação entre as mídias digitais - nas quais se incluem os aplicativos geossociais - e a economia criativa. Desvelarei que o problema desses conceitos previamente mencionados é a falta de consideração das particularidades culturais de outras sociedades, nas quais regimes de controle da sexualidade criam obstáculos ainda mais robustos ao desenvolvimento. Ao ignorarem a especificidade de regimes de exclusão de outras regiões, propagarem tais conceitos como "universais" e estimularem o uso de tais conceitos na formulação de políticas públicas, tais autores marginalizam a permanência de padrões homofóbicos e heteronormativos em outras regiões do planeta e relegam à invisibilidade aqueles que não se enquadram nos estereótipos heteronormativos culturalmente definidos. Nesse contexto, os aplicativos geossociais gays não inibem esses estereótipos, mas criam condições de possibilidade para que eles se fortaleçam.

A seguir, apresentarei o resultado da pesquisa executada no Grindr e no Scruff em quatro territórios criativos do Rio de Janeiro: o Distrito Criativo do Porto, no Centro, sub-região que abriga o principal polo criativo da cidade; a rua Voluntários da Pátria e suas imediações, em Botafogo - o maior polo criativo da Zona Sul e o segundo maior da cidade -, nas quais estão situadas algumas das mais importantes produtoras de audiovisual e de eventos, empresas de design e desenvolvedoras de softwares do município (GRILLO, 2013); o Polo Rio Cine \& Vídeo, que fica localizado entre a Barra da Tijuca e Jacarepaguá, na Zona Oeste, e reúne produção cinematográfica, computação gráfica, transmissão de dados e pós-produção; e São Cristóvão, na Zona Norte, em especial nos arredores da Quinta da Boa Vista - onde se realizam eventos de moda e se localizam inúmeras empresas desse setor - e do Centro Municipal Luiz Gonzaga de Tradições Nordestinas, que reúne empreendimentos dos setores criativos do artesanato e da gastronomia, além de produtoras de TV e cinema no seu entorno e nas proximidades.

A pesquisa foi executada entre os meses de março e junho de 2016, nos quais foram examinados cerca de 80 perfis de Grindr e Scruff - em torno de 20 em cada território - e conversei com alguns usuários por meio dos chats dos próprios aplicativos e do aplicativo WhatsApp. Nos perfis e/ou nos chats, cerca de 20 se identificavam como profissionais criativos que atuavam em setores como design, publicidade, audiovisual, fotografia e gastronomia. Foram considerados perfis tanto de profissionais criativos que trabalham nesses territórios ou nas proximidades como de moradores, visitantes e frequentadores dessas regiões, tendo em vista que, de acordo com os parâmetros definidos na literatura, a "tolerância" deveria vigorar entre aqueles que trabalham nas indústrias criativas e se estender para a população que habita e circula por tais territórios. Além dos procedimentos online, realizei entrevistas presenciais semiestruturadas com quatro homens que utilizam ou já utilizaram pelo menos um dos aplicativos de redes geossociais gays e frequentam os territórios em questão. Dois deles têm relação direta com atividades profissionais em indústrias criativas, como explorarei adiante.

Finalmente, examinarei como o Rio de Janeiro desenvolveu uma infraestrutura bruta para as indústrias criativas, mas avançou pouco em termos da educação para o respeito às diferenças e da consolidação de políticas e legislação para a defesa de indivíduos LGBT, o que cria obstáculos para a aceitação plena da diferença e a valorização na sua especificidade, necessárias à expressão da criatividade.

\section{A criatividade que não fala português: as limitações dos conceitos norte-atlânticos}

Para o especialista britânico Charles Landry (2011, p.10-11, 14-15), um território criativo - que pode ser um polo, um bairro, uma região, uma cidade ou um 
estado da federação - deve ser dotado de vitalidade pela valorização de seus patrimônio e identidade para projetar seus presente e futuro, além de empreendedorismo, conectividade - em particular meios físicos e tecnológicos que aproximem habitantes e minimizem conflitos - e aceitação explícita das diferenças. O próprio Landry, em parceria com Franco Bianchini (LANDRY; BIANCHINI, 1995), aplicou a noção de "território criativo" ao espaço das cidades, utilizando o conceito de "cidade criativa" para se referir a municípios nos quais profissionais dos setores criativos desempenhavam papel central e a imaginação estabelecia os traços e o espírito dos lugares. A formulação dos conceitos levava em conta a revitalização de indústrias culturais para o desenvolvimento de espaços urbanos no Reino Unido, um processo que também trouxe inovações urbanas em setores como saúde, educação e segurança pública. A ideia de "cidade criativa" estendeuse, a partir da experiência britânica e de outras áreas na Europa e nos EUA, para se referir a espaços urbanos em que a interação entre as indústrias criativas e o governo permitiu desenvolver uma efervescência cultural que atrai profissionais criativos para um fluxo mais rico e uma maior densidade de ideias, estimula a multiplicidade de perspectivas - que viabiliza que as ideias sejam fertilizadas pela interação - e fortalece a capacidade criativa de empresas e instituições (CCTC, s.d). Na perspectiva desenvolvida pela literatura norte-atlântica à luz das experiências europeias e norte-americanas, um projeto de desenvolvimento baseado no conceito de "cidade criativa" viabilizaria o combate às desigualdades e à violência, a revitalização de áreas degradadas e a promoção de concentrações de instituições públicas e privadas para apoio a empreendimentos e inclusão social (FOORD, 2008, p.91-93, 111).

Entretanto, grande parte da literatura norteatlântica ignora que, no mundo periférico, as condições de possibilidade para o desenvolvimento pleno de cidades criativas não se colocam ou se mostram precárias, tendo em vista o desconhecimento do potencial das atividades criativas nos Estados mais pobres, a ausência de instituições voltadas para economia criativa nesses locais, a concentração global de produção e distribuição dos bens criativos nos Estados Unidos e na Europa e o alinhamento deficiente das políticas públicas setoriais (DUQUE, 2015, p.495-497; MIGUEZ, 2007, p.107-109; SANTOS, 2015, p.1447-1448). Os contrastes socioeconômicos se casam às dificuldades de financiamento para empreendimentos criativos - em geral associados a alto risco -, à inadequação de marcos regulatórios para atividades desses setores e às inadequações no processo educacional para o desenvolvimento de habilidades específicas. Ademais, o estímulo a indústrias criativas no mundo em desenvolvimento apresenta um potencial ainda mais amplo de gentrificação - fenômeno de ocupação de áreas das cidades por população de alta renda, que desloca os habitantes originais de menor remuneração que viviam nesses locais -, bem como de desestabilização das relações sociais locais e de marginalização de empreendimentos criativos pequenos e médios (REIS, 2008, p.26, 35-46).

Florida (2002) - um dos principais autores norteamericanos da área de estudos sobre Economia Criativa - fala da existência, nas cidades criativas, de uma "classe criativa", composta por trabalhadores do conhecimento que lideram a geração de riqueza por meio do intelecto e da criatividade (FLORIDA, 2002). O crescimento socioeconômico seria determinado pela conjunção de seus três Ts: talento - que dirige esse crescimento -, tecnologia - fundamental para que se estabeleçam conexões e interação entre pessoas - e tolerância, fundamental na atração de capital humano (FLORIDA, 2005; OLIVEIRA et al., 2013, p.22-23). No que diz respeito especificamente ao processo criativo, a tolerância pode estar associada à justiça social, destacando-se a inclusão de grupos discriminados, como mulheres, gays e minorias étnicas. A gestão das diferenças poderia gerar benefícios na produtividade e na lucratividade para empreendimentos criativos ao permitir o amplo recrutamento de talentos, o fortalecimento da inteligência de mercado e maior habilidade na solução de controvérsias. Todavia, Florida não observa que mudanças procedimentais formais de comportamento não necessariamente transformam as crenças e as atitudes que perpetuam a discriminação. A busca de igualdade mostra-se concentrada em organizações específicas, além de que as reivindicações para maior participação de grupos diversos baseadas nas necessidades das empresas podem fazer com que os níveis de igualdade se tornem mais vulneráveis a flutuações econômicas (PROCTOR-THOMSON, 2009, p.83-93). As leis e as políticas que protegem trabalhadores criativos são desprezadas mesmo em Estados norte-atlânticos. 
Inúmeros profissionais trabalham em regime autônomo, tendo condições contratuais desfavoráveis e precárias, com retornos financeiros incertos (BENDASSOLLI; WOOD JR., 2010, p.260-264, 268-273). Ainda que reconheça a pluralidade de indivíduos e setores que compõem a classe criativa, Florida parece conceber que os seus componentes estariam todos homogeneamente alocados em termos da distribuição da renda e do acesso a oportunidades. Entretanto, não lida com as características, as necessidades e as dificuldades particulares dos profissionais de cada setor, em especial a forma como as diferenças de raça, etnia, faixa etária, gênero e orientação sexual se manifestam especificamente em cada indústria e como as hierarquias criadas em torno delas geram obstáculos para seus componentes em termos de acesso a oportunidades particularmente em cada setor criativo.

Florida (2002; 2005, p.72-73) argumenta que a atração e a mobilização de talentos criativos permitiriam o desenvolvimento de um ambiente aberto e inclusivo nos territórios e nas cidades criativas ao viabilizarem que as pessoas sejam elas mesmas e validem suas identidades múltiplas, fazendo com que a tolerância nos setores criativos transbordasse para os cidadãos daquelas cidades. Entretanto, os exemplos utilizados por Florida para o desenvolvimento de seu argumento focam prioritariamente em espaços localizados na região norteatlântica. Cidades do mundo em desenvolvimento ilustram alguns de seus argumentos, mas de maneira superficial e homogeneizante em relação ao tratamento oferecido às norte-atlânticas. $\mathrm{O}$ autor parece conceber que a existência de talentos criativos é uma das condições de possibilidade dadas e não-problematizadas em qualquer cidade criativa, sem, contudo, levar em conta que tal fator pode ser insuficiente ou mesmo irrelevante para o desenvolvimento de mais tolerância em face de regimes de controle social que vigoram em cada sociedade e nos quais até mesmo profissionais criativos podem estar imersos.

A própria noção de tolerância - colocada como fundamental a uma cidade criativa - é problemática, na medida em que implica coexistência e convivência, não a aceitação ou o reconhecimento pleno da diferença e a valorização na sua especificidade. A retórica da diversidade mantém intacta a cultura dominante que marginaliza os outros (MISKOLCI, 2016, p.50-51). Assim, o pleno desenvolvimento de uma cidade criativa e do potencial econômico da criatividade exige ir além da tolerância para a incorporação efetiva da diferença. Entretanto, a literatura ignora esse ponto, bem como a especificidade cultural dos obstáculos socioeconômicos e políticos ao desenvolvimento de cidades criativas no mundo em desenvolvimento, em particular os regimes de controle social em sociedades fora do eixo norte-atlântico. Nos Estados em desenvolvimento, pode-se dizer que leis e instituições que deveriam proteger trabalhadores criativos são ainda mais flexíveis, e aquelas que deveriam proteger a população LGBT são, em geral, mais frágeis ou mesmo inexistentes. No que diz respeito ao mercado de trabalho, o perfil crônico de heterogeneidade, precariedade e desigualdade reproduz-se também na economia criativa, tendo em vista a oferta estruturalmente abundante de mão de obra, a difusão parcial de relações de trabalho de assalariamento formal, a duração elevada das jornadas de trabalho, os níveis baixos de remuneração, a grande dispersão entre os rendimentos do trabalho e suas evidentes segmentação ou discriminação em termos de gênero, raça, idade e grau de instrução (TAFNER, 2006, p.424-426).

No que diz respeito às identidades de gênero $e$ às orientações sexuais em cidades criativas - e também partindo de uma análise de experiências do contexto norte-atlântico -, Charles J. Ten Brink (2012) argumenta que a presença de uma "comunidade LGBT visível, aceita e integrada" estimula a saúde social e fiscal de uma cidade criativa, de forma que as regras para a regulação do uso da terra devem ser adaptadas a fim de se eliminarem ou minimizarem efeitos heteronormativos e se atraírem membros da classe criativa (BRINK, 2012, p.791). Elizabeth Bernstein (2010, p.28-31) argumenta que as mudanças no âmbito da sexualidade estão amplamente relacionadas às alterações na estrutura de trabalho e produção em São Francisco, uma cidade criativa na qual se desenvolve uma sociedade pós-industrial baseada em serviços e associada ao retorno de empreendedores ligados a setores criativos, à alta tecnologia e à inovação. No contexto da contracultura, a cidade abrigou indivíduos LGBT desde a década de 1970 e, ao se tornar um centro de novas tecnologias desde o desenvolvimento de um parque tecnológico em torno da Universidade de Stanford na região do Vale do Silício, atraiu profissionais altamente qualificados de indústrias criativas como design, arquitetura e softwares, sendo grande parte deles homens 
homossexuais. As redes de comunicação viabilizadas por tais tecnologias foram baseadas em interesses e desejos dos usuários, e, no caso de São Francisco, a maior densidade dessas redes foi possível pelo fato de haver maior desenvolvimento de tecnologia na cultura de empreendedorismo vigente - cuja base individualista no liberalismo econômico orienta as maneiras de se viver, produzir e consumir - e na maior facilidade de acesso a essas tecnologias. As mídias digitais materializadas em equipamentos móveis - que se tornaram possíveis graças ao avanço da microeletrônica - permitiram não apenas a criação de verdadeiras estações de trabalho em computadores portáteis e smartphones para profissionais criativos, mas o desenvolvimento de espaços relacionais para a socialização e a criação de laços amorosos e sexuais.

Comparando o caso de São Francisco à realidade brasileira - em particular, à de São Paulo -, Richard Miskolci (2014, p.279-282) argumenta que a cidade norte-americana apresenta um acesso maior a espaços de socialização gay - como bares e boates - e os serviços de telefonia e internet são bem mais baratos do que em cidades brasileiras, de forma que, nos aplicativos geossociais, a classe criativa em São Francisco desenvolve meios de segmentação social sofisticados em relação a raça, classe social e faixa etária. Ainda que a sociedade norteamericana pareça menos hierárquica que a brasileira, o autor observa que a demanda por "discrição" em contextos profissionais, familiares e educacionais também ocorre nos EUA por conta da busca de melhor aceitação em certos espaços, de maneira que as condenações culturais e políticas às homossexualidades fazem com que os meios técnicos desenvolvam espaços para contatos homoafetivos e homoeróticos separados da dimensão pública (MISKOLCI, 2014, p.279-282).

A realidade no mundo em desenvolvimento na aplicação de estratégias de "cidades criativas" enfrenta obstáculos ainda maiores no que diz respeito à promoção da aceitação plena das diferenças em termos de orientações sexuais e identidades de gênero, em particular pela permanência de regimes de controle heteronormativos internalizados na legislação, nas políticas públicas e nas instituições sociais. Baseando-se no caso de Cingapura, Audrey Yue (2012) argumenta que, apesar do estímulo à liberalização cultural pela economia criativa, a homossexualidade é ilegal na cidade-estado, ainda que tolerada. Já Natalie Oswin (2012) aponta que os esforços para afastar a imagem autoritária do governo em Cingapura e estimular a economia criativa levaram a uma liberalização das expressões públicas da homossexualidade, mas a legislação e as políticas discriminatórias que afastam indivíduos LGBT da cidadania plena foram mantidas. Em obra posterior, a autora destaca que a função da família como uma ficção reguladora estimulada pelo Estado visa a produzir uma população de "cidadãos de qualidade" em contraposição àqueles que se mantêm fora da norma de família heterossexual sobre a qual os objetivos de desenvolvimento de Cingapura estão assentados (OSWIN, 2014).

No Brasil, a homossexualidade não é colocada como uma conduta criminosa desde os primeiros anos após a independência, e existem leis estaduais e municipais que combatem a discriminação por orientação sexual e identidade de gênero, particularmente em cidades criativas como São Paulo e Rio de Janeiro. Entretanto, o preconceito e a discriminação permanecem por convenções que hierarquizam as relações sociais ligadas a identidades de gênero e orientações sexuais como lícitas ou ilícitas e se mostram pouco ou nada afetadas pelo desenvolvimento de atividades relacionadas à economia criativa e pelo estímulo oficial às indústrias do setor. No caso da sociedade brasileira, a valorização predominante da masculinidade hegemônica faz com que o mundo virtual opere como um local de socialização homoerótica que abre a muitos homens uma oportunidade de criar um contexto de camaradagem com outros, no qual se reconhece a superioridade da masculinidade heterossexual, mas se permite o envolvimento sexual com outros homens. Com isso, tais homens visam a se proteger da exposição, da humilhação e dos maus tratos dos quais mulheres e "afeminados" são alvos (MISKOLCI, 2013, p.316-322). A necessidade de manutenção de uma posição de domínio e controle que os proteja de tais ameaças explica também por que mesmo homens que vivem abertamente a homossexualidade continuam a reiterar padrões heteronormativos. É também importante colocar que, ainda que exista a demanda por "discrição" também em Estados desenvolvidos e muitos desses Estados estejam longe de ser exemplares em termos de reconhecimento do potencial das diferenças, cidades criativas em Estados em desenvolvimento podem ter ainda mais barreiras políticas, 
legais e culturais à aceitação plena das diferenças de orientação sexual e identidade de gênero.

A consequência direta da marginalização da especificidade cultural de outras regiões por autores norteatlânticos se vê quando universalizam seus conceitos de maneira acrítica e os mobilizam para a formulação de políticas públicas em Estados em desenvolvimento: ao não atentarem para a particularidade dos regimes locais de exclusão, tais autores relegam em segundo plano a permanência de padrões homofóbicos e heteronormativos em inúmeras regiões do planeta, tornando invisíveis aqueles que não se enquadram nos estereótipos heteronormativos culturalmente definidos da masculinidade hegemônica.

"Quero homem com cara e jeito de macho": a heteronormatividade no Grindr e no Scruff em territórios criativos do Rio de Janeiro

Para iniciar a análise de perfis do Grindr e do Scruff nos territórios criativos em foco na pesquisa e viabilizar a interação com os usuários no Rio de Janeiro, utilizei perfis em que inseri como nickname a inicial de meu primeiro nome e uma foto que enquadrava apenas meu torso nu, de perfil másculo e atlético. Escolhi esse tipo de foto por ser o mais utilizado nos aplicativos por homens que se dizem "discretos" ou temem que sua busca homorientada por amizade, sexo ou relacionamento seja descoberta. Eles frequentemente inserem fotos de corpo inteiro ou de uma parte do corpo sem que a imagem exponha o rosto. Outros optam por fotos de paisagem ou mesmo nenhuma foto, não raramente sequer inserindo um nickname ou uma descrição de seus interesses e atributos físicos. Em algumas situações, fui abordado por usuários e, em outras, busquei a interação com indivíduos que se colocavam como "discretos" ou "fora do meio", buscavam sexo "no sigilo" ou "na encolha", inseriam descrições de seus perfis como "não sou nem curto afeminados" ou se definiam como "macho", "brother", "putão" ou mesmo "hetero". Muitos desses homens procuraram ressaltar características físicas identificadas nos padrões da masculinidade hegemônica, como "malhado" e "sarado". A maior parte se encontra na faixa etária de 25 a 50 anos e se define em seus nicknames e nas informações dos perfis por meio de aumentativos ("dotadão") ou superlativos ("ativasso") e de termos associados ao universo masculino ("malandro", "safado" ou "lek", forma reduzida de "moleque" para os mais jovens). Muitos termos se mostram associados a domínio, violência, agressividade ou superioridade, como "picudo", "socador de macho" ou "leitador" (em referência ao grande volume na ejaculação). Alguns utilizam emoticons nas próprias definições, como a mamadeira, a banana e a berinjela em referência a seus órgãos sexuais. Raramente tais homens ofereciam seus nomes verdadeiros em nicknames ou mesmo nas conversas no chat. Alguns mencionavam que namoravam ou eram casados com mulheres a fim de justificar a busca por sexo "na encolha". Alguns também informavam a profissão pelo perfil do Scruff, que permite uma descrição mais detalhada que a do Grindr. Procurei desenvolver uma interação mais constante com aqueles que apareciam com maior frequência em cada aplicativo toda vez em que eram iniciados nos territórios criativos durante o período da pesquisa, em especial os profissionais criativos.

Não raramente tais homens tinham perfis em ambos os aplicativos, inclusive utilizando as mesmas fotos e descrições. Em geral, as informações disponíveis já deixavam claras as preferências do usuário ("ativo", "passivo" ou "versátil", também denominado "flex") e os tipos de contato sexual que buscavam ("só punheta", "curto mamada", "quero meter o caralho em macho" ou "curto caralhar geral"). A maior parte se definiu como "ativo" ou "versátil", e muitos passivos destacaram seu claro repúdio aos afeminados nas autodescrições ("gosto de dar o cu, mas sou macho", "sou putinha na cama, mas macho na vida", "não mio", "tenho cara e jeito de homem", "não ando rebolando por aí"). Os afeminados são geralmente retratados como extravagantes pelos seus gostos musicais ("se vem dizendo que gosta de Lady Gaga, bloqueio na hora") e pela afeição por moda ("não a viadinhos fashionistas"), bem como pelos locais que frequentam ("se vc é daquelas que rebolam na boate, vaza!"). Alguns afirmam que não são nem curtem afeminados, mas não têm "nada contra" quem seja.

Não realizei encontros presenciais com os usuários captados pelos aplicativos, mas foi mantida a comunicação pelos chats ou pelo WhatsApp. Para aqueles com quem mantive interação mais constante, identifiqueime como pesquisador e apresentei o propósito da minha pesquisa, mas alguns não me responderam mais ou mesmo bloquearam meu perfil. A maior parte se dispôs 
a colaborar, desde que mantivesse o compromisso de proteger suas identidades reais e as utilizadas nos perfis. Nas conversas, a linguagem é direta e objetiva, permeada por emoticons e caracterizada por inúmeros palavrões, marcas da oralidade ("eae", "coé", "falaê"), erros de português ("afim" no sentido de "a fim") e gírias e frases bem típicas de sites e bate-papos gays na internet ("tem local ?", “o que tu curte?”). Alguns enviavam fotos que traziam o enquadramento completo do rosto, do pênis, das nádegas e do ânus. Inicialmente, tais homens solicitam descrições detalhadas e fotos, resistindo a oferecer as suas próprias e somente as liberando ao ver primeiramente as fotos do interlocutor.

Na proximidade do Distrito Criativo do Porto, havia perfis de homens que tinham educação de níveis médio e superior - grande parte estudante ou formada em Direito e Administração, principalmente - e trabalhavam em áreas administrativas de órgãos públicos ou setores técnicos na própria região. Muitos viviam na Zona Sul - em especial Copacabana -, em bairros da periferia da cidade ou em Niterói e cidades da Baixada Fluminense. Os nicknames e as autodescrições sinalizavam formas de identificação - "safado e putão", "socador ATV" -, bem como preferências e objetivos: "discreto que não curte afeminados", "somente pegação com macho", "quero meter e leitar dentro". A preocupação com a saúde e a forma física nas autodescrições - "sou zeloso com a saúde física e mental", "malho, corro e nado", "não aos 4:20, busco caras saudáveis", sendo “4:20” referência ao uso de maconha - era tão frequente quanto a preocupação em preservar o sigilo: "sigilaço", "Socialmente hetero. Sigilo total !", "Busco romance no sigilo, pois meus amigos não sabem que curto homens".

No que diz respeito a profissões ligadas à economia criativa, foi possível identificar, pelas informações nos perfis e conversas pelo chat, homens ligados ao setor de audiovisual, à publicidade, à produção artística e à fotografia na região portuária. Alguns chegavam a vender seus serviços pelos aplicativos, como um usuário que se dizia fotógrafo de nu masculino. Um cenógrafo de 42 anos informava em seu perfil do Scruff curtir apenas rapazes militares, atletas e discretos, preferências semelhantes às de um usuário de 26 anos que trabalhava em uma agência de produções artísticas nas proximidades da região portuária. Um fotógrafo cuja idade não pôde ser identificada e que se definia como "discreto" e "bissexual" alertava que o possível parceiro deveria ter a "postura do sexo que carrega". A heteronormatividade é visível também nos perfis de outros homens fora dos setores criativos, captados na zona portuária. Um dos usuários do Grindr afirma que "Se latir, tô dentro. Se miar, tô fora". A analogia do homem másculo com um cachorro e do afeminado com o gato evidencia a depreciação dos últimos, como se não cumprissem os critérios de virilidade e força valorizados pelo dono do perfil. Outro usuário colocou no perfil do Grindr que não curtia "afetados, afeminados, miados e pintosas". A reafirmação da própria masculinidade muitas vezes se dava com a depreciação das masculinidades de outros homens - "vários machões escrevem arrogâncias em seus perfis e na cama viram barbies" - ou o apelo a referenciais do universo masculino, como a utilização que um usuário fez do universo do futebol para justificar sua "fase passiva": "já fui atacante e meio de campo, mas ultimamente tenho preferido ficar no gol". Um de meus entrevistados presenciais, um funcionário público de 36 anos que frequenta atividades culturais da zona portuária e trabalhou por nove anos no Centro, disse que detestava os afeminados porque os associava à pobreza e ao fracasso profissional: "Tinha medo de não dar certo na vida e acabar virando essas bichinhas pão-com-ovo que são faxineiras, empregadas... Não é esse o tipo de gente que busco no Grindr".

$\mathrm{Na}$ Zona Sul da cidade, grande parte informava que tinha educação superior - muitos formados em Direito, Engenharia e Administração de Empresas, alguns até mestrandos e doutorandos - e morava em bairros da própria região, como Botafogo, Copacabana, Ipanema e Leblon. Nas conversas, muitos deles revelaram que pertenciam a famílias de classes média ou alta. Os abertamente homossexuais conheciam espaços de sociabilidade gay como boates e saunas, mas grande parte dizia desconhecer "o meio" e considerava esses espaços muito "cheios de viado". Foi possível perceber que a preservação da masculinidade hegemônica vinha acompanhada da sustentação de outras hierarquias sociais. Tais homens demonstraram atenção maior com a classe social - em geral evidenciada na rejeição a perfis a partir do local da residência do usuário em uma área pobre -, a faixa etária - muitos deixavam claro que não curtiam "novinhos" ou "maduros" / "coroas" -, o tipo físico - 
vários diziam detestar "gordos" ou "ursos" - e a formação cultural dos interlocutores, visível em inúmeros perfis captados em Botafogo: "Não sou chegado a conversas monossilábicas", "Pare de abreviar e aprenda a soletrar pois corta o tesão teclar com quem não dá a mínima para o português". A exigência com relação às qualidades do parceiro era consideravelmente maior na Zona Sul em relação aos demais territórios considerados, ainda vindo acompanhada da reiteração dos padrões heteronormativos: "sexo apenas com macho malhado que tenha prazer em levar pirocada", "aberto de sexo casual a namoro com o cara certo, que seja masculino, profissional, independente e que cuide do físico, da mente e da alma", "não procuro magrelos, fashionistas, viadinhos e afeminados". O desejo de submissão dos parceiros - sem, contudo, que eles deixassem de ser vistos como "machos" - pôde ser observado no perfil de um usuário do Scruff que se definia como "ativo dominador": "Você pode até falar que é macho e discreto, mas, quando fechar a porta do quarto, vai ser minha putinha submissa e obediente".

Dentre os profissionais criativos, foi possível perceber trabalhadores dos setores audiovisual e editorial, designers, fotógrafos e arquitetos. Um usuário do Scruff cuja idade não era identificada afirmava ser editor de uma revista internacional e documentarista, dividir sua vida entre o Rio de Janeiro e Los Angeles e gostar da "energia e do otimismo dos caras mais jovens", mas revelava ter preferência apenas por "atletas" e "rapazes sarados", preferências semelhantes às de um designer de 25 anos que dizia procurar "ativo ou passivo sem frescura", às um fotógrafo de 34 anos e às de um gastrônomo de 41 anos. A posição crítica aos afeminados ficou explícita no depoimento de um músico de 30 anos, gay, que entrevistei presencialmente e frequentava os ambientes culturais do bairro de Botafogo. Ele disse que a convivência com afeminados em ambientes criativos como os da música e das artes cênicas fez com que ele visse tais afeminados como "coisa corriqueira". Mesmo sendo um profissional da economia criativa, ele afirmava que sentiria vergonha de "andar com um afeminado com medo do olhar das pessoas". Para namoro, ele preferia "um homem com jeito de homem". "Se eu gostasse de mulher, ficava com uma", disse.

Uma posição parecida é assumida por um dos meus outros entrevistados presenciais, um homem gay de
31 anos que atua na área comercial de uma joalheria e mantém contatos sexuais com parceiros na Zona Oeste, que vivem próximos ao Polo Rio Cine \& Vídeo. Ele afirmou que tinha "nada contra" afeminados, mas que não era "muito adepto dos excessivamente afeminados para relacionamento afetivo e sexual". Ele confessou que já "tentou se abrir" para uma visão diferente, mas disse que "inconscientemente somos guiados a procurar os machos alfa". Nas buscas nos aplicativos, ele disse procurar homens "com aspecto de cuidados", mas que, ao ver um afeminado dentre os perfis, ele "deixa quieto". Para um relacionamento afetivo, apontava que seria hipócrita se dissesse que uma relação com um homem afeminado não the causaria vergonha por medo da desaprovação familiar e social. Como conviveu com inúmeros homens afeminados na sua formação acadêmica em Letras e artística como pianista, afirmava que afeminados poderiam ser "amigos com certeza", mas que, "numa relação amorosa, queremos o porto seguro", na sua visão um homem que não os expusesse tanto às pressões sociais e ao preconceito como um afeminado.

$\mathrm{Na}$ Zona Oeste, identifiquei inúmeros usuários que atribuíam prioridade à aparência física na seleção dos parceiros e nos seus próprios perfis, com fotos de seus corpos atléticos em academias, vestiários e praias ou descrições que faziam referências à prática de atividades físicas. As preferências reveladas nos perfis em geral remetiam ao padrão heteronormativo: "sexo só com macho", "quero caras ativos que sejam realmente homens e tenham disposição". Não raramente era possível perceber a reafirmação da própria masculinidade pelos passivos a fim de não se sentirem inferiores aos ativos pela sua condição ("[quero] cara macho que curta fazer outro macho de putinha na foda"), bem como a inferiorização da masculinidade dos outros homens pelos ativos ao colocá-los em posições sexuais tipicamente femininas, ainda que tais ativos reconhecessem seus parceiros como másculos na esfera pública: "[sou] tarado por grandões fardados e de academia que têm pinta de macho, mas na cama gemem, rebolam, gostam de uns tapas". Dentre os profissionais criativos, alguns se identificavam nos perfis do Scruff como produtores de TV e cinema, designers, publicitários e profissionais de moda e de gastronomia e buscavam predominantemente "rapazes militares", "atletas" e "rapazes sarados". 
Em São Cristóvão, poucos homens inseriam descrições completas em seus perfis, e alguns sequer inseriam fotos ou se dispuseram a informar suas profissões; dentre os profissionais criativos, havia especialmente artesãos, produtores de TV e gastrônomos. A maior parte inseria apenas a idade - de 25 a 40 anos em média - e a forma de contato sexual que desejava ("vem mamar", "macho X macho apenas", "procuro discrição e sigilo para foda"). Os nicknames e as autodescrições seguiam os padrões das outras áreas examinadas (“dominador", "hetero pirocudo", "macho de pegada", "lek discreto", "discreto e reservado", "sigilo porra: aqui não é bagunça"), mas eram mais frequentes as referências a outros marcadores de masculinidade, como a torcida por times de futebol ("Vascaíno", "Mengão"). Nos perfis, os usuários que não eram moradores de São Cristóvão em geral informavam que viviam em bairros mais pobres da Zona Norte Honório Gurgel, Pilares, Ramos, Penha e Bonsucesso, por exemplo - ou em cidades vizinhas, como Nova Iguaçu. Um dos meus entrevistados presenciais, um professor de Educação Física de 32 anos e estudante de Engenharia de Produção em uma universidade próxima a São Cristóvão, é gay, mas não revela sua orientação sexual para a família nem para colegas de faculdade. Ele deixou claro o repúdio a saunas, espaços que ele classifica como "sujos" e "de baixo nível": "Nunca fui [a uma sauna], mas tive amigos dos Estados Unidos que foram. Eles me disseram que lá o pessoal se pega em público... Acho nojento. Não condeno quem vai, mas não é para mim". A contenção do sexo gay à esfera privada - mesmo que fosse às cabines privativas da própria sauna - revelava a permanência da heteronormatividade na esfera pública, ainda que num espaço de socialização entre homens que buscam sexo com outros. Embora a Engenharia de Produção pudesse ser entendida como uma das indústrias criativas, ele disse que o ambiente profissional e acadêmico era muito "cheio de homem". Por isso, jamais falava sobre sua sexualidade com colegas da universidade por temer ser ridicularizado e excluído por eles e recorria ao Grindr a fim de encontrar secretamente parceiros a quem chamou de "amigos com benefícios".

Alguns dos usuários do Grindr e do Scruff em São Cristóvão se diziam comprometidos e manifestavam já nos perfis não querer envolvimento sentimental. Grande parte desses usuários se colocava como homens simples e criticava a hipervalorização nas autodescrições de outros usuários: "Muito sapo se achando príncipe", "Lembrese: o último biscoito do pacote está sempre quebrado". Nas suas buscas, indicavam que buscavam homens que seguiam os padrões heteronormativos ("sou homem e gosto de semelhantes na postura") e manifestavam a repulsa aos "afeminados", associados a "afetados" ou "frescos" ("nada de versáteis ou afeminados", "quero caras que curtam outros caras, mas que não sejam da batida gay", "Tem pinta ? Tô fora"). Eles valorizavam a educação e a cordialidade por parte dos interlocutores, reforçando o sentimento de camaradagem que procuravam construir com seus parceiros: "ereção e educação todos notam quando se tem". Um usuário do Scruff de 45 anos que se definia como "casado e puto" disse que não tinha paciência para "viados de cativeiro, que querem tudo na mão. Vão à caça !". As ideias de "caça" e de maturidade para enfrentar as decepções - "se não der certo... Frustração faz parte da vida" - mostram-se amplamente ligadas ao padrão de masculinidade heteronormativo exigido do homem brasileiro, que, como aponta Miskolci (2013, p.315), teria o direito de exercer sua sexualidade sem ter responsabilidade por quem se envolve com ele. A permanência de uma heteronormatividade velada fica clara na posição de um profissional criativo morador da região, um designer de interiores de 34 anos: ainda que dissesse que tinha "problema com nada", ele se definia como um "passivo discreto" e tinha clara preferência por homens másculos e viris.

\section{O "armário criativo" no Rio de Janeiro}

$\mathrm{Na}$ tentativa de compreender as motivações sociais, econômicas e culturais para a preferência pelo "não-afeminado" nos aplicativos geossociais gays no Rio de Janeiro, cumpre destacar problemas políticos e legais na estratégia de desenvolvimento humano adotada na cidade, amplamente pautada na economia criativa. Cabe entender inicialmente o conteúdo dessa estratégia. A economia criativa foi concebida pela prefeitura como um mecanismo para a transformação urbana e a inclusão social, um meio para desenvolvimento do capital cultural e uma plataforma para a construção de vitrine internacional para a atração de negócios e talentos (WANIS, 2013). Buscando o apoio dos governos federal e estadual, a 
prefeitura buscou se articular com as indústrias criativas e os produtores culturais para estabelecer um espaço para a fixação de profissionais, a valorização da diferença e a geração de pré-condições para empreendimentos, como se vê na revitalização de áreas degradadas como a zona portuária (APRIGIO, 2015, p.60; MERCHER, 2013, p.105). Para estimular o capital cultural, o governo municipal buscou ampliar a rede de espaços culturais públicos, fortalecer o acesso à cultura e, no que tange especificamente a economia criativa, focou no apoio a produção, comercialização, infraestrutura e treinamento, tendo destaque as áreas de cinema e TV (FIGUEIREDO, 2015, p.33-41; WORLD CITIES CULTURE FORUM, 2015). A divulgação da imagem da cidade no exterior assentou-se na realização de eventos socioculturais de grande porte vinculados à economia criativa, como os desfiles das escolas de samba durante o Carnaval e festivais musicais como o Rock in Rio, e de megaeventos esportivos como os Jogos Olímpicos e Paralímpicos de 2016, com potencial para abrir oportunidades para o desenvolvimento de setores criativos (APRIGIO, 2015, p.49-50, 80-83). Obras realizadas para abrigar espaços culturais - como o Imperator Centro Cultural João Nogueira no Meier e o novo Museu da Imagem e do Som na praia de Copacabana - atraem shows e exposições e auxiliam na fixação de profissionais criativos na cidade.

A promoção da economia criativa, no Rio de Janeiro, aparece ligada às tentativas de estimulo à aceitação plena da diferença em termos de orientação sexual e identidade de gênero por parte de seus moradores e visitantes. Em 2011, a Prefeitura lançou um pacote de ações contra a LGBTfobia, que incluiu a agilização do encaminhamento de casos de discriminação ao poder público, a divulgação de toda a legislação de proteção aos direitos LGBT na cidade, a capacitação e a inserção no mercado formal de trabalho de travestis e transgêneros e a visita de assistentes sociais e pedagogos a comunidades carentes para orientar a população sobre leis e direitos civis nas esferas municipal, estadual e federal. Um decreto assinado pelo prefeito Eduardo Paes garantia o direito a servidores e usuários dos serviços da prefeitura a usar o nome social. Um outro decreto previa a exposição de aviso em local visível ao público da Lei 2.475/1996, a lei antidiscriminação do município, em todos os postos de atendimento de serviços públicos municipais. A oferta de cursos de capacitação em estabelecimentos comerciais para orientar os funcionários sobre os direitos dos indivíduos LGBT fazia parte do pacote (LAURIANO, 2011). No âmbito do Estado do Rio de Janeiro, o Programa Rio sem Homofobia procura combater a discriminação e a violência contra a população LGBT e promover a sua cidadania em todo o território fluminense por meio da disseminação de informações sobre direitos e da produção, implementação e monitoramento de políticas públicas transversais, sendo que a capital conta com um dos centros de cidadania do programa (RIO SEM HOMOFOBIA, s.d.). Eleita como um dos melhores destinos gays para turistas por publicações internacionais, a cidade do Rio de Janeiro recebe um grande número de turistas LGBT de outras cidades do Brasil e do mundo ao longo do ano, em especial durante o Carnaval. Em 2014, eles foram responsáveis por $30,75 \%$ do setor de turismo na cidade (OLIVEIRA, 2014).

Os homens homossexuais vieram demonstrando a capacidade de delimitar territórios, ocupando locais e implantando signos ligados à sua identidade, como o trecho da praia de Copacabana em frente ao Hotel Copacabana Palace e a Rua Farme de Amoedo, em Ipanema, que também atrai turistas gays em épocas festivas como o Carnaval ou a Parada Gay. Podem-se mencionar também boates, bares e cafés localizados predominantemente no Centro e na Zona Sul. Além de um campo simbólico para o reconhecimento mútuo por seus semelhantes, muitos indivíduos buscam tais territórios de convivência como uma estratégia de proteção e de exercício pleno da sua identidade pelo medo do preconceito e da rejeição em outros locais (BARRETO, 2010, p.15-19). Certos homens interessados em práticas sexuais homorientadas preferem frequentar lugares com menor exposição, como cinemas pornográficos (a maior parte localizada no Centro), saunas (a maioria concentrada na Zona Sul), praias afastadas das regiões mais movimentadas da cidade (como as Praias da Reserva e de Abricó, esta dedicada ao nudismo, na Zona Oeste), parques e complexos de lazer (como o Aterro do Flamengo) e banheiros públicos de estações de transporte coletivo, universidades, hipermercados, estabelecimentos comerciais, centros empresariais e shopping centers, prática conhecida como "banheirão" (SOUZA, 2012). A apropriação de tais partes do espaço urbano permite a tais sujeitos exercer práticas homossexuais, mas estarem livres 
para circular pelas redes públicas nas quais se desenvolve o imperativo heterossexual (COSTA, 2010, p.22).

Ainda que tenha adotado estratégias de desenvolvimento de cidade criativa, o Rio de Janeiro ainda apresenta uma série de problemas que impedem o desenvolvimento pleno dos setores criativos. A cidade enfrenta um nível elevado de violência urbana, a precariedade do sistema de saúde e das redes de transporte e níveis elevados de degradação ambiental - como se vê na poluição da Baía de Guanabara -, o que dificulta a fixação e a mobilidade da classe criativa. A gentrificação de áreas urbanas onde potencialmente atividades criativas estimulariam o desenvolvimento local reforça o quadro de polarização social. No que diz respeito especificamente à economia criativa, são visíveis as dificuldades de financiamento de setores criativos, a inadequação de marcos regulatórios que garantam os direitos individuais de remuneração pela produção criativa e a permanência de um sistema educacional precário e ainda voltado para questões de ordem técnica (REIS, 2008, p.35-45).

As deficiências no desenvolvimento de meios intelectuais interferem diretamente no potencial criativo dos cidadãos e na construção de cidadania. Alguns homens com quem conversei, pelos aplicativos das redes geossociais, no desenvolvimento desta pesquisa acreditam que o processo educacional no Rio de Janeiro pareceu priorizar o conhecimento técnico em relação à capacidade de reflexão, ao raciocínio crítico e ao estímulo à criatividade dos estudantes. Em instituições públicas e particulares de ensinos fundamental e médio, disciplinas relacionadas ao ensino de artes, desenho, música e literatura não existem ou não acompanham todas as etapas de formação dos alunos, que muitas vezes as consideram irrelevantes ou se desinteressam por considerarem tais matérias pouco aplicáveis à sua vida cotidiana. Grande parte das instituições demonstra uma preocupação maior em cobrir critérios técnicos que atendam à necessidade de exames vestibulares e outras formas de ingresso na universidade, sem estimular a criatividade e a consciência crítica e cidadã dos estudantes. Iniciativas como feiras de artes, produção de material criativo e atividades complementares às aulas que estimulem o potencial criativo partem mais da iniciativa individual de professores do que de diretores de instituições de ensino ou de autoridades do setor. Em instituições públicas e particulares de ensino superior e cursos profissionalizantes de setores ligados à economia criativa, os estudantes observam a priorização do conhecimento técnico que atenda às demandas do mercado em prejuízo de abordagens teóricas mais críticas. "A gente vem para a faculdade aprender técnica. Tanto os alunos como os professores literalmente cagam para esse lance de teoria, de aprofundar a crítica", disse um usuário do Scruff, aluno do curso de Publicidade e Propaganda de uma conceituada universidade particular do Rio de Janeiro. Segundo um usuário do Grindr, formado em Design por uma universidade pública, "quem está na faculdade só quer mesmo é o conhecimento técnico que vai ser útil para você ser um bom profissional e, é claro, ter um diploma de universidade pública que o mercado valoriza". Ainda que reconhecessem que professores específicos atentassem para o debate sobre temáticas sociais e políticas, eles sinalizam que o estímulo à convivência harmônica com as diferenças - que contribuiria para uma noção mais inclusiva de cidadania - era mais resultado de um esforço individual de educadores do que das instituições de ensino. "Um ou outro professor trazia esses temas polêmicos para a gente discutir em sala, mas era raro isso acontecer. O pessoal só se interessava mesmo era em aprender técnica de cozinha", disse um aluno de um curso técnico profissionalizante em Gastronomia oferecido por uma entidade privada, em comunicação mantida comigo pelo WhatsApp. Mesmo reconhecendo que a sua universidade tinha iniciativas voltadas para a promoção do respeito às diferenças, o aluno de Publicidade e Propaganda apontou que um dos principais problemas é a falta de avaliação do resultado das iniciativas de inclusão social pela instituição: "A faculdade até tem seminários sobre as questões LGBT, mas também ninguém vem depois verificar se o cara entendeu o que ouviu na palestra e mudou a postura dele... A faculdade não muda o que vem de casa".

Em termos da aceitação plena de indivíduos LGBT, vê-se que muitas das iniciativas governamentais em níveis municipal e estadual vêm sofrendo com a falta de recursos financeiros - que culmina na demissão de funcionários, no atraso de pagamentos, no agravamento dos problemas de infraestrutura e na paralisação dos serviços oferecidos - e os interesses políticos, como a indicação do pastor Ezequiel Teixeira à Secretaria Estadual de Assistência Social e Direitos Humanos. Teixeira posicionou-se contra causas do movimento LGBT e 
promoveu o desmantelamento do Rio sem Homofobia em 2016. Na cidade do Rio de Janeiro, a violência verbal e física contra a população LGBT continua intensa, sendo o ambiente familiar e o grupo de amizades aqueles em que os homossexuais mais sofrem agressões. O ambiente de trabalho e a escola também se configuram como áreas em que homossexuais são vítimas de piadas, xingamentos, agressões e todo tipo de humilhações. De acordo com o Rio sem Homofobia, permanece também, no imaginário de indivíduos homofóbicos, a expectativa de impunidade ou de punições brandas pela violência que cometem, como o pagamento de cestas básicas (LISBOA, 2013). A homofobia visível nas representações estigmatizantes da homossexualidade por policiais, promotores, juízes e advogados vem transpassada por outras hierarquias e clivagens sociais em relação às vítimas da violência homofóbica - como as baseadas em raça ou classe social - e muitas vezes implica a impunidade dos acusados de violência contra gays. Ainda que a condenação moral da homossexualidade dificilmente implique impunidade daqueles que cometeram violência letal contra homossexuais, a tendência em culpabilizar a vítima por conta de sua homossexualidade permanece viva não apenas nos discursos dos defensores dos acusados, mas da própria sociedade (CARRARA; VIANNA, 2001). Assim, inúmeros homens - independentemente da orientação sexual que assumam na esfera pública - buscam preservar sua posição de domínio e controle e reforçar padrões heteronormativos a fim de se protegerem de ameaças às quais mulheres e "afeminados" são mais expostos na sociedade carioca. A manutenção desses padrões no Rio de Janeiro desenvolve criativamente um "regime de armário" particular que impede a aceitação plena da diferença necessária a uma cidade criativa e tem nos aplicativos de redes geossociais gays uma ferramenta que reforça a superioridade da masculinidade heterossexual, mas viabiliza o contato homoerótico e homoafetivo.

\section{Considerações finais}

Como os depoimentos coletados na pesquisa demonstram, o regime de controle da sexualidade abarca um sistema de normas que fazem do espaço público um ambiente de heterossexualidade e destinam ao privado as relações entre pessoas do mesmo sexo, de forma que a homossexualidade deva ser vivida "em segredo" (SEDGWICK, 2007, p.30). Miskolci (2013, p.302-303, 310) argumenta que homens que buscam relações afetivas e sexuais como outros e se enquadram nos padrões heteronormativos em plataformas virtuais procuram se conformar a expectativas historicamente criadas de que as relações homossexuais devem ser restritas à vida privada e omitidas no espaço público e procuram não ser reconhecidos como homossexuais publicamente. A predação sexual de tipos físicos másculos por meio dos aplicativos geossociais viriliza esses homens ao afastá-los do estigma do "afeminado", associado frequentemente à homossexualidade (MISKOLCI, 2013, p.302-303; 2014, p.286-290). Ainda que no Brasil a tecnologia seja mais cara e menos disseminada do que em Estados desenvolvidos, ela gerou condições para vivências homoeróticas e homoafetivas mais seguras não apenas por conta da violência homofóbica, mas pela menor aceitação plena das múltiplas orientações sexuais no Rio de Janeiro em comparação a cidades tipicamente analisadas pela literatura norte-atlântica. Muitas dessas cidades inclusive estão longe de ser paraísos de respeito às diferenças como muitos autores norte-americanos e europeus da área de estudos de economia criativa parecem conceber, mas, ainda assim, não apresentam tantas barreiras políticas, legais e culturais que se colocam na sociedade carioca.

Como esta pesquisa evidenciou no caso de aplicativos de redes geossociais gays, mesmo homens homossexuais que vivem abertamente sua sexualidade valorizam e cultuam a masculinidade hegemônica associada à heteronormatividade e ainda a sustentam juntamente a outras hierarquias sociais no Rio de Janeiro. Ainda que a heteronormatividade não seja compatível com os pilares da economia criativa, o culto à masculinidade hegemônica ligada a um corpo másculo e viril e a depreciação dos "afeminados" continuam a ser reproduzidos por usuários de aplicativos gays em territórios criativos - independentemente da orientação sexual que assumem na esfera pública -, desvelando a permanência de um regime excludente que contraria a lógica de respeito e aceitação plena das diferenças, necessária à expressão do potencial socioeconômico da criatividade e aos efetivos reconhecimento e respeito da diferença na dimensão de riqueza na cidade do Rio de Janeiro. Como coloca Miskolci (2014, p.289), a tecnologia 
presente nos aplicativos de redes geossociais gays não eliminou as desigualdades já existentes, mas as realocou para as relações mediadas e as reforçou.

\section{Referências bibliográficas}

APRIGIO, André Edson Ribeiro de Souza. A paradiplomacia e a atuação internacional de governos subnacionais. Dissertação - Mestrado em Relações Internacionais. Departamento de Relações Internacionais e Administração Pública, Escola de Economia e Gestão, Universidade do Minho, 2015.

BARRETO, Rafael Chaves Vasconcelos. Geografia da diversidade: breve análise das territorialidades homossexuaisnoRiode Janeiro. Revista Latinoamericana de Geografia e Gênero, v.1, n.1, p.14-20, jan./jul.2010.

BENDASSOLLI, Pedro F.; WOOD JR., Thomaz. O paradoxo de Mozart: carreiras nas indústrias criativas. Organizações \& Sociedade, v.17, n.53, p.259-277, abr./ jun. 2010.

BERNSTEIN, Elizabeth. Temporarily yours: intimacy, authenticity, and the commerce of sex. Chicago: The University of Chicago Press, 2010.

BRINK, Charles J. Ten. Gayborhoods: Intersections of Land Use Regulation, Sexual Minorities, and the Creative Class. Georgia State University Law Review, v.28, n.3, p.789-849, 2012.

BUTLER, Judith. Bodies that Matter: on the discursive limits of sex. Nova York: Routledge, 2003.

\section{CARRARA, Sérgio; VIANNA, Adriana R.} B. Homossexualidade, violência e justiça: a violência letal contra homossexuais no município do Rio de Janeiro. Relatório de pesquisa. IMS/UERJ/Fundação Ford, 2001.

CCTC. Cidade criativa. CCTC website, s.d. Disponível em: < http://cidadecriativa.org/pt/cidade-criativa $>$. Acesso em: 8 set. 2013.
CONNELL, R.W. Masculinities. Cambridge: Polity Press, 1995.

.; MESSERSCHMIDT, J.W. Hegemonic masculinity: Rethinking the Concept. Gender \& Society, v.19, n.6, p.829-859, dez. 2005.

COSTA, Benhur Pinós da. Geografias das Representações Sobre o Homoerotismo. Revista Latinoamericana de Geografia e Gênero, v.1, n.1, p.21-38, jan./jul. 2010.

DAMIANI, Amélia. Geografia Política e Novas Territorialidades. In: PONTUSCHKA, Nídia Nacib; OLIVEIRA, Ariovaldo Umbelino de. (Org.) Geografia em Perspectiva. São Paulo: Contexto, 2002, p.17-26.

DONALDSON, Mike. What Is Hegemonic Masculinity? Theory and Society, v.22, n.5, p.643-657, out.1993.

DUQUE, Felipe da Silva. Economia criativa: empreendimentos culturais. In: CALABRE, Lia; SIQUEIRA, Mauricio; LIMA, Deborah Rebello; ZIMBRÃO, Adélia (Org.) Anais do VI Seminário Internacional de Políticas Culturais. Rio de Janeiro: Fundação Casa de Rui Barbosa, 26-29 maio 2015, p.487497.

FIGUEIREDO, João Luiz de. Economia criativa, cidade criativa e desenvolvimento. In: TEIXEIRA, Eduardo Ariel de Souza; CORRÊA, Sílvia Borges (Org.). Economia criativa. Coleção Contextos e Pesquisas. Rio de Janeiro: E-papers, 2015, p.27-47.

FLORIDA, Richard. The rise of the creative class and how it's transforming work, leisure, community and everyday life. Nova York: Basic Books, 2002.

. The flight of the creative class: the new global competition for talent. Nova York: Harper Collins, 2005.

FOORD, Jo. Strategies for creative industries: an international review. Creative Industries Journal, v.1, n.2, p.91-113, 2008. 
GRILLO, Marco. Região de Botafogo é o segundo maior polo da indústria criativa na cidade. O Globo, 18 abr. 2013. Disponível em: <http:/oglobo.globo.com/rio/ bairros/regiao-de-botafogo-o-segundo-maior-polo-daindustria-criativa-na-cidade-8126343\#ixzz4A5VnRfzj>. Acesso em: 29 maio 2016.

JESUS, Diego Santos Vieira de. O mundo fora do armário: teoria queer e Relações Internacionais. Ártemis, v.XVII, n.1, p.41-50, jan./jun. 2014.

; KAMLOT, Daniel. Economia Criativa e Políticas

Públicas. Curitiba: Prismas, 2016.

LANDRY, Charles. Prefácio. In: REIS, Ana Carla Fonseca; KAGEYAMA, Peter (Org.) Cidades criativas: perspectivas. São Paulo: Garimpo de Soluções, 2011, p.7-15.

; BIANCHINI, Franco. The creative city. Londres: Demos, 1998.

LAURIANO, Carolina. Novo site informa agenda LGBT e recebe denúncias on-line no Rio. G1, 18 maio 2011. Disponível em: <http://g1.globo.com/rio-de-janeiro/ noticia/2011/05/novo-site-informa-agenda-lgbt-e-recebedenuncias-line-no-rio.html>. Acesso em: 27 maio 2016.

LISBOA, Vinícius. Ambiente familiar é o local onde homossexuais mais sofrem agressões. Agência Brasil, 17 maio 2013. Disponível em: <http://www.ebc.com. br/noticias/brasil/2013/05/ambiente-familiar-e-o-localonde-homossexuais-mais-sofrem-agressoes $>$. Acesso em: 28 maio 2016.

MÈRCHER, Leonardo. Museu de Arte do Rio e Museu do Amanhã: duas ferramentas à paradiplomacia cultural do Rio de Janeiro. In: MONTEIRO, R. H.; ROCHA, C. (Org.). Anais do VI Seminário Nacional de Pesquisa em Arte e Cultura Visual. Goiânia: UFG, FAV, 2013, p.101-111.

MIGUEZ, Paulo. Economia criativa: uma discussão preliminar. In: NUSSBAUMER, Gisele Marchiori (Org.) Teorias e políticas da cultura: visões multidisciplinares. Salvador: EDUFBA, 2007, p.95-113.
MISKOLCI, Richard. Machos e Brothers: uma etnografia sobre o armário em relações homoeróticas masculinas criadas on-line. Estudos Feministas, v.21, n.1, p.301324, jan./abr.2013.

- San Francisco e a nova economia do desejo. Lua Nova, v.91, p.269-295, 2014.

. Teoria Queer: um aprendizado pelas diferenças. 2 ed. Belo Horizonte: Autêntica, 2016.

OLIVEIRA, Pâmela. Gays foram responsáveis por 30\% da receita do Rio com turismo no carnaval. Veja, 2 abr. 2014. Disponível em: <http://veja.abril.com.br/noticia/economia/ gays-foram-responsaveis-por-30-da-receita-do-rio-comturismo-no-carnaval>. Acesso em: 27 maio 2016.

OLIVEIRA, João Maria de; ARAÚJO, Bruno Cesar de; SILVA, Leandro Valério. Panorama da Economia Criativa no Brasil. Texto para discussão / Instituto de Pesquisa Econômica Aplicada, n.1880. Rio de Janeiro: IPEA, out.2013, p.1-49.

OSWIN, Natalie. The Queer Time of Creative Urbanism: Family, Futurity, and Global City Singapore. Environment and Planning A, v.44, n.7, p.1624-1640, jul.2012.

. Queer time in global city Singapore: Neoliberal futures and the 'freedom to love'. Sexualities, v.17, n.4, p.412-433, jun.2014.

PERLONGHER, Néstor. O negócio do michê: a prostituição viril em São Paulo. São Paulo: Fundação Perseu Abramo, 2008.

PROCTOR-THOMSON, Sarah Belle. Creative differences: the performativity of gender in the digital media sector. Tese - PhD em Gender and Women's Studies. Centre for Gender and Women's Studies, Lancaster University, Lancaster, 2009.

REIS, Ana Carla Fonseca. Introdução. In: (Org.)

Economia criativa como estratégia de desenvolvimento: uma visão dos países em desenvolvimento. São Paulo: Itaú Cultural, 2008, p.14-49. 
RIO SEM HOMOFOBIA. O programa. RSH website, s.d. Disponível em: <http://www.riosemhomofobia.rj.gov. br/secao/sobre/o-programa>. Acesso em: 28 maio 2016.

SANTOS, Valcir Bispo. A relação entre cultura e desenvolvimento e a estratégia de fomento de arranjos criativos na Amazônia. In: CALABRE, Lia; SIQUEIRA, Mauricio; LIMA, Deborah Rebello; ZIMBRÃO, Adélia (Org.) Anais do VI Seminário Internacional de Políticas Culturais. Rio de Janeiro: Fundação Casa de Rui Barbosa, 26-29 maio 2015, p.1439-1453.

SEDGWICK, Eve Kosofsky. Epistemologia do armário. Cadernos Pagu, n. 28, p. 19-54, 2007.

SEN, Amartya. Desenvolvimento como liberdade. São Paulo: Companhia das Letras, 2000.

SILVA, Francisco Raniere Moreira da. As relações entre cultura e desenvolvimento e a economia criativa: reflexões sobre a realidade brasileira. NAU Social, v.3, n.4, p.111121, maio/out. 2012.

SOUZA, Tedson da Silva. Fazer banheirão: as dinâmicas das interações homoeróticas nos sanitários públicos da Estação da Lapa e adjacências. Dissertação - Mestrado em Antropologia. Faculdade de Filosofia e Ciências Humanas, Universidade Federal da Bahia, 2012.

TAFNER, Paulo. Políticas Públicas de Emprego, Trabalho e Renda no Brasil. In: . (Ed.) Brasil: o estado de uma nação. Rio de Janeiro: IPEA, 2006, p.397-446.

WANIS, Amanda. Cidade Criativa: política urbana e cultural na reconstrução simbólica do Rio Olímpico. II Conferência Internacional Megaeventos e a Cidade. Rio de Janeiro, 27-30 abr. 2013. Disponível em: <http:// megaeventos.ettern.ippur.ufrj.br/sites/default/files/ artigos-cientificos/wanis_a._cidade_criativa.pdf $>$. Acesso em: 1 maio 2016.

WORLD CITIES CULTURE FORUM. Rio de Janeiro, 2015. Disponível em: <http://www. worldcitiescultureforum.com/cities/rio-de-janeiro $>$. Acesso em: 23 out. 2015.
YUE, Audrey. Queer Singapore: A critical introduction. In: ; ZUBILLAGA-POW, Jun (Ed.). Queer Singapore: illiberal citizenships and mediated cultures. Hong Kong: Hong Kong University Press, 2012, p.1-25.

Recebido em: 27/06/2017.

Aceito: 27/07/2017. 